\title{
Repatriate Children's Readjustment to the Home Country and the Impact on Repatriates
}

\author{
Mahazir Ismail ${ }^{1}$, Anees Janee $\mathrm{Ali}^{2}$ \& Mohd Rizaimy Shaharudin ${ }^{1}$ \\ ${ }^{1}$ Faculty of Business Management, Universiti Teknologi MARA Kedah, Merbok, Kedah, Malaysia \\ ${ }^{2}$ School of Management, Universiti Sains Malaysia, Pulau Pinang, Malaysia \\ Correspondence: Mohd Rizaimy Shaharudin, Faculty of Business Management, Universiti Teknologi MARA \\ Kedah, 08400 Merbok, Kedah, Malaysia. Tel: 60-4-456-2000. E-mail: rizaimy@kedah.uitm.edu.my
}

\author{
Received: April 6, 2015 Accepted: October 21, 2015 Online Published: October 26, 2015 \\ doi:10.5539/ass.v11n25p25 URL: http://dx.doi.org/10.5539/ass.v11n25p25
}

\begin{abstract}
The aim of the study is to examine the effect of the readjustment of repatriate children on their home country. There are many antecedents that are related to repatriate children's readjustment. However, individual-related factors specific to the repatriate children are the main focus of the present study. For repatriate children, we found that satisfaction with new friends and acquaintances is significantly related to their psychological well-being and general readjustment to the home country. Furthermore, dismissive-avoidant attachment style among repatriate children is negatively and significantly related to repatriates' well-being. The present study indicates that repatriate children's readjustment to the home country is imperative for repatriates' own readjustment process. The repatriates' psychological well-being was found to have been significantly related to their spouses' well-being and children's general readjustment. In addition, the present study findings highlight that it is compulsory for repatriates to take into consideration the performance of the readjustment practices among their family members when they return to their own country. Such consideration is important in view of the impact of the readjustment process of their family to their career achievement in their home country.
\end{abstract}

Keywords: repatriate children's, readjustment, psychological well-being, general readjustment, working readjustment

\section{Introduction}

Repatriation is defined as re-entering one's home country after their extended stay in another country for the purpose of study or work (Hunt \& Bolon, 1998). Repatriation is the opposite of expatriation. It involves the moves of expatriates back to the home country from their respective international assignment. Examples of reasons why expatriates return home include: having completed their assignments, they wish for their children to be educated in schools back home; not being happy with the overseas' assignment that they decide to return home; or failing to carry out their assignments at satisfactory levels so they have to be sent home.

The repatriation process is distinct from other forms of relocation. Repatriates may encounter many difficulties upon returning home. Despite the growing recognition of its impact on successful expatriate management, the repatriation process continues to be a source of frustration to many human resource managers and also expatriates (Paik, Segaud, \& Malinowski, 2000). Most repatriates find that upon returning to their home country, their standard of living often declines and they often face the lack of appreciation for the knowledge they have gained overseas. Without a clear use of their skills, repatriates often suffer from a lack of direction and purpose.

Expatriates who come back from international assignments do not know exactly what they have accomplished during the past few years and they also do not know how to use their international knowledge appropriately (Solomon, 1995). Returning expatriates also have to look for an appropriate position within the organization where they are always placed in a temporary position or lower than what they had held prior to the overseas assignments (Stroh, Gregersen, \& Black, 1998).

In addition, returning to the home country may be a strain to the whole family. Fish and Wood (1997) and Siljanen (2009) identified 'the lack of support for partner's readjustment to the home country' as a critical factor. Black and Stephen (1989) suggested that 16 to 40 percent expatriate failures are due the failure of the spouse/partner to adjust. Family/psychological problems experienced by the repatriate families include the 
reduction in lifestyle, disorientation to the culture, loss of social contact with family and friends while away and the children's problems in adjusting to school (Harvey, 1989; Hunt \& Bolon, 1998). Thus, the researcher would argue that repatriates who are not able to readjust probably are having spouses/partners who are not able to readjust too. When it is decided for expatriates to return to their home country, this refers to the removal of personal effects, breaking ties with colleagues and friends at the host country.

Repatriating children may find that they also need to readjust to their home country. Dowling, Welch \& Schular (1999) mentioned that it is normal for repatriate children to find that the re-entry to their home country is difficult. The educational system in the home country may not be equivalent to the private international schools or to the schools they go to in the host country. Peer groups may have changed which can cause the repatriate children to be tremendously anxious and intimidated. In addition, children being out of touch with the current slang, sports, and fashion, may struggle to regain acceptance into the new peer group. Having been brought up overseas, readjusting back to the home country's educational system may be especially problematic. Even worse, a study even asserted that some of the returning Japanese teenagers committed suicide after failing to make the grades back home (Peng, 2009).

Hence, the preceding discussions have triggered the following objectives of the study:

- To study the relationship between repatriate children's individual satisfaction variables (namely the satisfaction with the new school, satisfaction with new friends and acquaintances; satisfaction with host country's oral pleasures (foods, drinks and language) and their home country readjustment.

- To examine the relationship between repatriate children's attachment styles (which are secure, dismissive avoidant, preoccupied, fearful-avoidant) and their home country readjustment.

- To investigate the relationship between repatriate children's readjustment to the home country and repatriates' readjustment to the home country.

\section{Literature Review}

\subsection{Repatriates' Readjustment to Home Country}

According to Black (1988); Oberg (1960), the intercultural adaptation/adjustment can be described as "the extent of psychological comfort with various aspects of a host country". In most general terms, intercultural adaptation deals with the changes that happened among individuals or groups to correspond to the surrounding demands. Thus, the researcher would argue that expatriates who then become repatriates, may also face similar situations in order to readapt and readjust to their own home country. By studying the definitions of intercultural adaptation/adjustment suggested by Zhang and Rentz (1996), the researcher would define readjustment to the home country as referring to repatriates' skills to re-adapt to the home environment sufficiently and efficiently and live comfortably as the repatriates normally do.

In addition, there is a distinction between psychological and socio-cultural adaptation (Searle \& Ward, 1990). Psychological adaptation can be associated with internal psychological outcomes such as mental health and personal satisfaction. On the other hand, socio-cultural adaptation/general adjustment is related to the internal psychological outcomes connecting individuals to their new situations such as the ability to deal with everyday issues, especially involving family life, work and school (Seagall, Dasen, Berry, \& Poortinga, 1999).

Since the researcher has argued that repatriates need to go through the process of readjustment like what expatriates have to go through, the researchers rename the indicators of readjustments as psychological well-being and general readjustment in order to fit into the context of the present study. In addition, work readjustment was added as another dimension of readjustment for repatriates as has been proposed by Black, Gregersen and Mendenhall (1992) and Parker and McEvoy (1993). Therefore, these three dimensions of readjustment; psychological well-being, general readjustment and work readjustment will be used as dimensions of repatriates' readjustment (that is, as the dependent variables in the present study). Based on these dimensions, it can be inferred that in order for repatriates to readjust to their home country, they have to be psychologically ready, able to live effectively in their daily lives, and are willing to readjust to match with their work situations. Meanwhile, for repatriate children, the dimensions for their readjustment are general health and general readjustment.

\subsection{Readjustment among Repatriate Children}

Repatriate children may feel disoriented with the changing culture and environment that have occurred in the home country while they are away living in other countries. Some were born in these countries and it will be a great change for them when they have to follow their parents back to their home country. This situation will 
make it harder for them to adapt themselves to the home country when all this while, they have been so used to the environment, things and situations in the host country.

\subsection{Satisfaction with the New School in the Home Country}

For some repatriate children who have developed the fluency of the local language and have been exposed to friends and culture of the host country, they may find it hard to adjust to the 'new' and 'strange' home country's environment and language. For some, it is a devastating experience. Some cannot even understand the local language that is used as a medium at school. Not being able to communicate in the local language, some repatriate children may feel left out at school. In addition, the method of teaching employed at the local school in the home country may be different from what the repatriate children have been made used to in the host country. This creates another problem to repatriate children. There were cases reported by repatriate children through our interviews that some of their teachers at schools did not understand their situations. For example, some teachers were angry because of their differences like, for example, having big handwriting and some teachers became angry when the repatriate children tried to correct the English adopted by their teachers. There were cases where these repatriate children acted out their anger by being violent at school and at home. Thus, repatriate children who were not satisfied with their schools in the home country may somewhat affect their readjustment process in the home country.

\subsection{Satisfaction with New Friends and Acquaintances in the Home Country}

One repatriate child from Malaysia who had lived in London and Toronto for six years told researcher that during the first few months coming home, she really wanted to return to Toronto, she was badly missing her many good friends and her previous school. She mentioned that it was very difficult to make friends in the home country because she felt that the children at school were jealous of her because she had just returned from overseas and her parents had occupied a higher position in the society. In addition, she spoke English fluently and this had made it harder for her to make new friends at school or in their neighbourhood. It was a difficult and painful experience for her. To make it harder for her at that time, she did not speak Malay language fluently to start making friends.

When the expatriate children are relocated to their home country, it is not necessary that they stay in the same places where they have resided before they are relocated. Thus, they have to make new friends and acquaintances. This process may take some time if the repatriate children are not prepared with the changes that happen in their home country while they are away. They may have some expectations of what the local people of the home country would be like before they are repatriated, but the real and current situation in the home county can be totally different from their expectations. Feeling frustrated with the hardships of making new friends and acquaintances, repatriate children may feel unhappy and they may find this situation harder for them to be satisfied socially.

The researcher would argue that repatriate children would face the challenge of losing good friends that they have made in the host country. Leaving good friends behind may be a very painful experience for some repatriate children. The hard time they face in order to make new friends in the home country may affect their readjustment process. Not satisfied with new friends and acquaintances in the home country may negatively impact the process of readjustment among repatriate children in the home country.

\subsection{Satisfaction with Host Country's Oral Pleasure (Food, Drinks and Language) for Repatriate Children}

Interestingly, one repatriate child told the researchers that it was very difficult for her when she returned home to Kedah in Malaysia when she spoke English with a Canadian accent and nobody wanted to try to understand her. She was having culture shock when children at school spoke in different Malay dialects. For example, the Kelantanese speak in their dialect and the same with both Penangites and Kedahans who speak in their own dialects. Having no friends who could speak in English with her had made her sad. The pleasure that she had to be able to communicate in English was not able to be continued in the home country. This situation had led her to have very few friends in the home country.

Usunier (1998) carried out an interesting research on expatriates' experiences of developing habits related to the absence of their native language, and eating and drinking habits in the host country. It was found that it affects the expatriates' overall satisfaction with the expatriation experiences. Usunier (1998) who conducted a research among American expatriates in France evidenced that an oral pleasure deficiency assesses the negative relationship between this deficiency and the expatriate's personal satisfaction.

In this context, the researcher would propose that the reverse situation may occur to repatriates. After spending many years in the host country, repatriate children may have tried different foods, drinks, and also the host 
country's language. When they return to their home country, these foods and drinks may not be available. In addition, the host country's language may not be used or may not be present or available at all in the home country. The acquired skill of the new language and the tastes of foods and drinks may make repatriate children long for them. Through the host country's language, some repatriate children may have developed good friendships with local people that may have become their best friends in the host country. Hofstede (1997) mentioned that by learning the language of the host country and being able to express oneself in another language, it means that he/she learns to adopt someone else's reference frame. In addition, the communication process in the host country may have been practiced openly and freely and some repatriate children may have enjoyed these communication styles. When they return to their home country, the communication process may be a little bit difficult for them, especially for those who live in countries with high power distance cultures.

\subsection{Attachment Styles}

The next antecedent of repatriate children's readjustment to the home country examined in the study is the attachment styles. According to Bartholomew and Horowitz (1991), attachment styles can be categorised into four kinds of styles which include the secure attachment, dismissive-avoidant attachment, preoccupied attachment and fearful-avoidant attachment style (Bartholomew \& Horowitz, 1991).

Interestingly, Bartholomew (1990) proposed a model that can be associated with the attachment style of adults. He suggested that a child develops attachment styles during his/her childhood which would then prolong the whole duration of a person's life. Besides that, Bartholomew (1990) also has differentiated the four attachments patterns into two distinct dimensions, namely, positive and negative patterns of a person's self, and positive and negative patterns of others. Subsequently, Bartholomew and Horowitz (1991) in their study termed the dimensions as secure attachment styles, dismissive avoidant attachment style, preoccupied attachment style, and fearful-avoidant ambivalent attachment style.

According to Bartholomew and Horowitz (1991), for secure attachment, people typically show a sense of worthiness (lovability) plus an anticipation that other people would generally accept and become responsive. Moreover, being self-confident and having no hard feelings towards others are common traits among the people. The result of the study shows that persons with secure attachment carry themselves more positively and rationally, possess the ability to solve problems, are capable to absorb pressure, and believe that they can get help from others in times of need. As a result, with these qualities, they would be able to handle stress with superiority, select suitable and effective strategies and leverage the support from other people to deal with pressures (Mikulincer \& Florian, 1998).

On the other hand, dismissive-avoidant attachment style is related to the people that possess a sense of love worthiness that is mixed together with a negative character about other people. These people avoid the frustration in their relationships with other people by the refusal of close relationships, freedom in life and independence. For individuals with a preoccupied attachment style, the traits include a sense of unworthiness (unlovability) that come together with a positive evaluation of others. This mixture of characteristics allows individuals to endeavour in favour of getting the acceptance from other people. Finally, the fearful-avoidant attachment style is explicitly demonstrated by the persons with a sense of unworthiness (unlovability) that is mixed together with an expectation that other people will reject the relationship due to unfaithfulness and non-dependability. Individuals with dismissive-avoidant and fearful-avoidant attachment styles typically create less connection with other people.

A study from Van der Zee, Ali and Haaksma (2007) examined the influence of family and parental work factors, personality, and attachment styles on the intercultural adjustment among 104 international expatriate children and adolescents. A secure attachment style was found to dominate as the strongest predictor of intercultural adjustment, whereby ambivalent attachment style was negatively related to their intercultural aspect in the host country adjustment. Interestingly, the beneficial effects of a healthy family and work situation were particularly found among children high on the secure attachment style. Based on the study, the researcher would assume that repatriate children, who are the main respondents of the present study will show the same result when attachment styles are studied among them. Being up to date, there is a dearth of study that has been carried out about attachment styles among repatriate children.

In the home country with new challenging environment and changes, repatriate children may have to make extra effort in order to make contact with other people, namely their relatives, friends and neighbours. Hence, the researcher anticipated that repatriate children who demonstrate dismissive-avoidant attachment style, a preoccupied attachment style, and a fearful-avoidant attachment style would be less effective in readjusting to their home country compared to repatriate children with secure attachment style. Repatriate children with 
dismissive-avoidant, preoccupied or/and fearful-avoidant attachment styles show a negative disposition toward other people and would tend to feel unlovable. These conditions will make it hard for repatriate children to be in touch with other children and any other people. Without having new friends which are a very tough circumstance for them to experience, these repatriate children may find it hard to trust others and would feel disappointed in the new environment of their own home country. Thus, the researcher would argue that repatriate children with dismissive-avoidant, preoccupied or/and fearful avoidant attachment styles will find it challenging for them to readjust to their home country.

\subsection{The Impact of Repatriate Children's Readjustment to the Home Country}

The difficulties of children to readjust to the home country may make repatriates themselves feel uncomfortable. Gregersen and Stroh (1997) mentioned that if repatriates have difficulty adjusting to their home country a "spillover" effect is expected, in which the repatriate readjustment is affected. It is a vis-à-vis effect whereby if the repatriates are not able to readjust successfully, it will give an impact to the readjustment process of the repatriates. Thus, readjustment levels of both the repatriates and their spouses are positively associated with one another (Gregersen \& Stroh, 1997). Engen (1995) mentioned that teh lack of repatriation assistance appears to be a costly oversight for companies, as data suggest that spousal and family repatriation readjustment has an enormous and positive impact on employees' adjustment to work. Thus, the researcher would strongly argue that if repatriate children are having difficulties in readjusting to the home country (in this case, their psychological well-being and general health are low and they are not able to readjust to the general elements in the home country), it will leave a negative direct impact on the repatriates' readjustment process.

Hence, in view of the preceding discussions, the following hypotheses have been developed for further investigation:

a) Hypothesis 1: The level of satisfaction with new school in the home country is positively related to repatriate children's readjustment to their home country.

b) Hypothesis 2: Satisfaction with new friends and acquaintances in the home country is positively related to repatriate children's readjustment process to their home country

c) Hypothesis 3: Missing the oral pleasures (foods, drinks and language) of the host country is negatively related to the readjustment process of repatriate children.

d) Hypotheses 4: A dismissive-avoidant attachment style, preoccupied attachment style, and fearful-avoidant attachment style are negatively associated with repatriate children's readjustment process, however, a secure attachment style is positively associated with the readjustment process.

e) Hypothesis 5: Repatriate children's readjustment is positively related to repatriates' readjustment to the home country.

\section{Methodology}

\subsection{Sampling}

The sample of the present study involved repatriates from all over the world. Repatriate children were invited to participate in the present study through the consent of their parents. The questionnaire for both the parent and the child were handed out to the parents. With the parent's consent, the questionnaire was given to his/her children. However, the researcher limits the scope of the sample to repatriates who have returned to their home country within one to two years because by referring to the U-curve Theory of Adjustment, repatriates and their families are assumed to have some ups and downs within the first few months of returning. By doing so, the researcher hopes that they have fresh memories recalling their experiences of readjusting to the home country as they answer the questionnaire. In addition, the samples of the present study must have lived overseas for at least one year. For children, the researcher had restricted the respondents to be those aged between 10-18 years old since the researcher is of the opinion that this range of age is deemed able to comprehend and answer the questionnaire given to them.

\subsection{Data Collection Method}

The present study involved extensive surveys with structured questionnaires as a major means of data collection. Questionnaires were developed based on the reviewed literature and from the outcomes of the interviews with the international companies' staff, repatriates and friends who have been expatriates before. Past research questionnaires and measurements were used and a few were adapted in order to develop questionnaires suited to the present topic. Later, pilot interviews were carried out to test the suitability of the developed questionnaires. For the pilot interviews, the researcher contacted and got in touch with four repatriate families. The pilot study 
with the repatriates and their families were carried out in persons through researcher's visits to their offices and homes. They were free to answer the questions while at the same time telling their experiences of the readjustment process. They were also free to give their ideas and opinion of what their companies could do to assist them to readjust to the home country.

The answers and experiences gained from the pilot study were used for the revision of the final version of the questionnaires. The final version of the questionnaire was fully structured. The Likert scale was used to measure the items: (5) strongly agree, (4) agree, (3) neutral, (2) disagree and (1) strongly disagree. The researcher sent out 500 questionnaires through parents of the repatriate children. Permissions were sought from the parents in order for both a parent and a child to participate in the present study. The researchers hoped to get useable returns of about 200 to 400 which is about 20 to 40 percent.

The Snowballing technique was also applied. Organizations that deal directly with expatriates and repatriates all over the world were contacted. Personal visits were made to The Outpost The Haque in The Netherlands, The Outpost Miri in Sarawak, The Outpost Alabang, in The Philippines, American Women Centre in The Haque and American Women Centre in Manila, The Philippines. In addition Petronas, Shell International, Telekom Malaysia, International Schools such as Dalat International School in Penang, Malaysia were also visited in which questionnaires were distributed.

\section{Results and Discussions}

\subsection{Profile of Respondents}

This study has sampled repatriate parents and children. The respondents' profile would be explained based on two groups of respondents where 500 questionnaires were distributed and 131 pairs of questionnaires (one pair refers to one parent and a child) had been returned. In the regression analysis, 131 units of sample were used for further analysis, and the 131 units were the total number of 'repatriate- child' couples that were compatible.

\subsection{Profile of Repatriate Children}

As shown in Table 1, a total of 131 repatriate children were involved in the present study, 65 children (49.6\%) were boys and 66 respondents $(50.4 \%)$ were girls. With regard to age, 56 children $(42.7 \%)$ were 10 to 15 years old and 75 respondents $(57.3 \%)$ were 16 to 18 years old.

Table 1. Profile of repatriate children

\begin{tabular}{lll}
\hline Gender & $\mathrm{N}$ & $\%$ \\
\hline Boy & 65 & 49.6 \\
Girl & 66 & 50.4 \\
Total & 131 & 100 \\
\hline Age & & \\
\hline $10-15$ years & 56 & 42.7 \\
$16-18$ years & 75 & 57.3 \\
\hline Total & 131 & 100 \\
\hline
\end{tabular}

\subsection{Reliability of Repatriate Children}

As Hair, Anderson, Tatham \& Black (2006) suggested, the Cronbach alpha coefficient of construct is ideally more than .70, but the Cronbach alpha for each item in the construct is good at .60. If a construct consists of 5 to 10 items, .60 value of Cronbach's alpha is acceptable, and when a construct consists of less than 5 items and below, the alpha value for .50 is acceptable. This Cronbach's alpha value means that the items in each domain are understood by most respondents. The result of the reliability analysis shows that the constructs of general health, general readjustment, satisfaction with new schools, satisfaction with new friends, satisfaction with host country's oral pleasure (food, drinks and language), secure attachment, and preoccupied attachment obtain an acceptable Cronbach's Alpha value. Meanwhile, fearful attachment and dismissive attachment have yielded low alpha value. However, Hair et al. (2006) suggested that the construct is still confident to be employed when the loading factor of every item is more than .30. By referring to Hair et al. (2006), the constructs preoccupied and fearful attachments were considerably valid to be employed in this research. The details of the findings are shown in Table 2. 
Table 2. Reliability analysis of repatriate children's

\begin{tabular}{llll}
\hline Types of Variables for Repatriate Children & Cronbach's Alpha & Mean & Std. Deviation \\
\hline General health & .79 & 2.98 & .49 \\
General readjustment & .78 & 3.08 & .61 \\
Satisfaction with new school & .67 & 3.19 & .58 \\
Satisfaction with new friends & .56 & 3.09 & .52 \\
Satisfaction with oral pleasure & .60 & 2.94 & .51 \\
Secure attachment styles & .62 & 3.06 & .37 \\
Fearful attachment styles & .37 & 3.08 & .61 \\
Dismissive attachment styles & .30 & 3.12 & .58 \\
Preoccupied attachment styles & .55 & 3.09 & .73 \\
\hline
\end{tabular}

\subsection{Reliability for Repatriates}

The result of the reliability analysis shows that the Cronbach's Alpha of instrument for repatriates in every construct is acceptable. The findings are shown in Table 3.

Table 3. Reliability analysis of repatriate

\begin{tabular}{llll}
\hline Types of Variables for Repatriates & Cronbach Alpha & Mean & Std. Deviation \\
\hline Psychological well-being & .62 & 3.08 & .90 \\
General readjustment & .83 & 3.34 & .65 \\
Working readjustment & .79 & 3.27 & .78 \\
\hline
\end{tabular}

\section{Inferential Statistics}

\subsection{Correlation}

The Pearson Product-Moment Correlation was applied to investigate the inter-correlations among all the study variables used to test the hypotheses. The details of the result are shown in Table 4.

Table 4. Correlation among variables in the children study

\begin{tabular}{lll}
\hline Major Variable Study & 1 & 2 \\
\hline 1.Psychological wellbeing & & \\
2.General readjustment & $\mathbf{. 5 5}^{* *}$ & \\
3.Working readjustment & $\mathbf{. 5 1}^{* *}$ & $.55^{* *} . \mathbf{5 5} 5^{* *}$ \\
\hline
\end{tabular}

Note. ${ }^{*} \mathrm{p}<0.05, * * \mathrm{p}<0.01$

The values indicate that Repatriates' psychological well-being is positively correlated at the range of .24 to .54 with all other variables (general readjustment, working readjustment) and the correlation is highly significant at $p<.01$.

It was found that Repatriate General Readjustment is positively correlated at the range of .51 to .55 with all other variables (general adjustment, working adjustment) and the correlation is highly significant at $p<.01$. The finding is displayed in Table 5.

\subsection{Hierarchical Regression}

A 2-Step hierarchical regression was used to test the hypothesis regarding the relationship between the level of satisfaction with the new school in the home country, satisfaction with new friends and acquaintances, satisfaction with oral pleasures, secure attachment, dismissive-avoidant attachment, preoccupied attachment and fearful-avoidance attachment of the host country with repatriate children's general health in their home country. The control variables consisted of the children's age and the total time spent in overseas were entered in Step 1 and all independent variables entered in Step 2. 
Table 5. Summary of the hierarchical multiple regression for repatriate children's readjustment

\begin{tabular}{|c|c|c|c|c|}
\hline \multirow{3}{*}{ Independent Variables } & \multicolumn{2}{|c|}{ General Health } & \multicolumn{2}{|c|}{ General Readjustment } \\
\hline & Std Beta & Std Beta & Std Beta & Std Beta \\
\hline & Step 1 & Step2 & Step 1 & Step2 \\
\hline \multicolumn{5}{|l|}{ Control Variables } \\
\hline Children's age & $.16^{*}$ & $.16^{*}$ & $.22 * *$ & $.23 * * *$ \\
\hline Total time spent overseas & .07 & .06 & .13 & .06 \\
\hline \multicolumn{5}{|l|}{ Model Variables } \\
\hline Satisfaction with new school & & -.03 & & -.07 \\
\hline Satisfaction with new friends and acquaintances & & $.19 * *$ & & $.45^{* * *}$ \\
\hline Oral pleasure (foods, drinks and language). & & -.05 & & -.01 \\
\hline Secure & & -.03 & & .05 \\
\hline Fearful-avoidance & & -.01 & & .13 \\
\hline Dismissive-avoidant & & $-.16^{*}$ & & .03 \\
\hline Preoccupied & & .01 & & -.03 \\
\hline $\mathrm{R}^{2}$ & & .03 & & .08 \\
\hline Adjusted $\mathrm{R}^{2}$ & & .02 & & .06 \\
\hline $\mathrm{R}^{2}$ Change & & .03 & & .08 \\
\hline Sig. F Change & & .09 & & .01 \\
\hline Durbin Watson Index & & 1.60 & & 2.00 \\
\hline
\end{tabular}

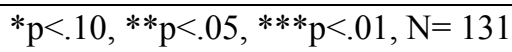

Table 5 shows the result of the Regression analysis. The result shows there are significant variants that affect children's age $(\beta=.16 \mathrm{Sig} .=p<.10)$ to the relationship between the antecedents and independent variables. However there is no effect given by the total time spent overseas to the relationship between antecedents and independent variables.

The findings also show that there are significant variants (positive relationship) of satisfaction with new friends $(\beta=.19$, Sig. $=p<.05)$ and negative relationship of dismissive- avoidance attachment style $(\beta=-.16$, Sig. $=p<.10)$ on repatriate children's general health. However, there is no significant variants (relationship) of satisfaction with new school $(\beta=-.03$, Sig. $=p>.10)$, satisfaction with oral pleasure $(\beta=-.05$, Sig. $=p>.10)$, secure attachment $(\beta=-.03$, Sig. $=p>.10)$, fearful attachment $($ Beta $=-.01$, Sig. $=p>.10)$, and preoccupied attachment style $(\beta=.01$, Sig. $=\mathrm{p}>.10)$.

Table 6. Summary of the hierarchical multiple regression for repatriates' readjustment

\begin{tabular}{|c|c|c|c|}
\hline $\begin{array}{l}\text { Independent Variables } \\
\text { Variables) }\end{array}$ & $\begin{array}{l}\text { Psychological } \\
\text { well-being } \\
\text { Std Beta }\end{array}$ & $\begin{array}{l}\text { General } \\
\text { readjustment } \\
\text { Std Beta }\end{array}$ & $\begin{array}{l}\text { Working } \\
\text { readjustment } \\
\text { Std Beta }\end{array}$ \\
\hline Children General Health & $\begin{array}{l}-.01 \\
\end{array}$ & -.06 & -.08 \\
\hline Children General Readjustment & $.22 * * *$ & .14 & .30 \\
\hline $\mathrm{R}^{2}$ & .40 & .28 & .45 \\
\hline Adjusted $\mathrm{R}^{2}$ & .38 & .26 & .43 \\
\hline $\mathrm{R}^{2}$ Change & .40 & .28 & .45 \\
\hline Sig. F Change & .00 & .00 & .00 \\
\hline Durbin Watson Index & 2.02 & 1.56 & 2.12 \\
\hline
\end{tabular}

${ }^{*} \mathrm{p}<.10, * * \mathrm{p}<.05, * * * \mathrm{p}<.01, \mathrm{~N}=131$

The result shows that there is a significant variant effect of children age $(\beta=.23$, Sig. $=p>.05)$ to the relationship between independent variables and dependent variables. However, there is no effect given by the total time spent 
overseas $(\beta=.06$, Sig. $=p>.10)$ to the relationship between independent variables and dependent variables.

Furthermore, the findings also show that there are significant variants (direct relationship) of satisfaction with new friends and acquaintances $(\beta=.45$, Sig. $=p<.01)$ on children's general readjustment. However, there are no significant variants (relationship) of satisfaction with new school $(\beta=-.07, \mathrm{Sig} .=\mathrm{p}>.10)$, satisfaction with host country's oral pleasure $(\beta=-.01$, Sig. $=p>.10)$, secure attachment $(\beta=-.05$, Sig. $=p>.10)$, dismissive-avoidant attachment $(\beta=-.03$, Sig. $=p>.10)$, preoccupied attachment $(\beta=.-03$, Sig. $=p>.10)$ and fearful attachment style $(\beta=.13$, Sig. $=p>.10)$.

Table 6 shows the result of the multiple regressions of children's general health and their general readjustment with regard to repatriates' wellbeing. The result of the multiple regression method shows that there are significant variants (relationship) of children's general readjustment $(\beta=.22$, sig. $<.01)$ upon their general psychological well-being. However, there is no significant variant of children's general health $(B e t a=-.01, p>.10)$ on repatriates' psychological wellbeing.

The result of the multiple regressions of children's general health and children's general readjustment regarding the repatriates' general readjustment has been analysed. However, it was found that there is no significant relationship between children's general health $(\beta=-.06, p>.10)$ and children's general readjustment $(\beta=.14, p>.10)$ on repatriates' general readjustment

In addition, the multiple regression of the spouse's psychological well-being and general readjustment, children's general health and children's general readjustment in regard of repatriates' work readjustment is also assessed. The result of the multiple regression method shows that there are no significant variants (relationship) of spouse's psychological well-being $(\beta=.36, \mathrm{p}<.01)$, children's general readjustment $(\beta=.30$, sig. $<.01)$ and children's general health $(\beta=-.06, p>.10)$ on repatriates' work-readjustment.

\section{Discussion}

\subsection{Repatriate Children's Attachment Styles and Their General Health}

The results from the present study showed that the hypothesis regarding repatriate children's attachment styles and their general health is partially accepted. Out of the four attachment styles, dismissive-avoidance showed negative and significant effects on repatriate children's general health. Bathlomew and Horowitz (1991) mentioned that individuals with dismissive avoidance attachment styles suggest a sense of love-worthiness that is mixed together with a negative character against other people. The researcher could conclude that repatriate children with the dismissive-avoidant attachment style need more attention from their parents and support since the present study indicates that repatriate children with the dismissive- avoidance attachment style would be the most negatively affected by the readjustment process especially to their general health.

Surprisingly, Ali (2003) and Van der Zee et al. (2007) found that the dismissive-avoidant attachment style among expatriate children showed significant effects with the intercultural adaptation to their host country. The present study also found that dismissive-avoidant is the strongest predictor among all the attachment styles towards repatriate children's readjustment process to their home country. This finding showed that repatriate children who are afraid to be too close to others will suffer in their friendships and thus will affect their general health.

Repatriate children, at the beginning, have to leave their friends in the home country when they have to follow their parents to move overseas to become expatriates. When the expatriation expires, again, repatriate children have to leave their friends that they have made in the host country. Leaving good friends behind may leave bad experiences to repatriate children. Thus, some repatriate children develop this dismissive-avoidance attachment style, that is, they signify a sense of love worthiness but which comes together with a negative character towards other people (Batholomew \& Horowitz, 1991). In this context, the repatriate children defend themselves against frustration by staying away from building close relationships with other people. They have so much love but they are scared to develop relationships with other children. They fear that by having a relationship, it will hurt their feelings later on whenever they have to say goodbye. Therefore, they avoid making friendship with other children. Thus, repatriate children with this attachment style need more attention from their parents in order to support them to go through the readjustment process.

\subsection{Repatriate Children's Individual Satisfaction and Their General Readjustment}

The results from the present study showed that the relationship between repatriate children's satisfaction antecedents and their general readjustment is partially accepted. From the present study, repatriate children's satisfaction with new friends and acquaintances in the home country is significantly related to their general readjustment. This is in line with Rokeach (1973) and Schwartz (1992) in which they mentioned that true friendship is one of the major elements of values. This suggests that in order to readjust to the home country, 
repatriate children need to be satisfied with the new friends and acquaintances in the home country. Through these new friends, repatriate children are able to take up hobbies and join in the recreational activities that they like. On top of that, the new friends will introduce them to many things and facets of the home country that repatriate children have never encountered. These new friends will be their resources in getting information and give them ideas to do things in order to fulfil their curious, developing minds. Thus, being satisfied with new friends and acquaintances who share the same likings in terms of music, fashion, hobbies, sports and other activities are crucial for repatriate children to readjust to the home country (Peng, 2009).

However, the satisfaction with the new school in the home country was found to have no relationship to repatriate children's general readjustment. In addition, repatriate children's satisfaction with host country's oral pleasures (in terms of food, drinks and language) was also found to have no relationship with their general readjustment. The researcher would argue that in terms of the new school in the home country, the repatriate children were continuing their process of learning and have no choice but to study at the school to which their parents send them. Thus, there was no significant relationship between the satisfaction with new schools and repatriate children's general readjustment. Regarding host country's oral pleasures, repatriate children did not show any significant relationship to their general readjustment because repatriate children would just have to follow and eat whatever their parents serve them. In terms of the language, repatriate children, typically being children who are bright and full of energy would quickly learn the new language. Thus, the researcher concludes that repatriate children's satisfaction with host country's oral pleasures (in terms of food, drinks and language) was found to be not significantly related to their general readjustment.

\subsection{Repatriate Children Attachment Styles and Their General Readjustment}

The researcher found that repatriate children's attachment styles have no significant relationship with children's general readjustment. Children attachment styles are more towards the psychological aspects of repatriate children's life whereas general readjustment is referred to external things like teacher, weather and friends to the children and not related to repatriate children psychologically. Thus, these two dimensions are not significantly related.

\subsection{Repatriate Children's Readjustment and Repatriates' Readjustment}

In this section, the relationships between repatriate children's readjustment and repatriates' readjustment are presented and discussed.

\subsection{Repatriate Children's Readjustment and Repatriates' Readjustment}

Surprisingly, the findings in the present study show that repatriate children's general health and repatriates' psychological well-being; repatriate children's general health and repatriates' general readjustment; repatriate children's general health and repatriates' work readjustment; repatriate children's general readjustment and repatriates' general readjustment and; repatriate children's general readjustment and repatriates' work readjustment have no significant relationships. This could be due to the fact that repatriates would mostly tend to leave children's matters to their spouses to handle. Furthermore, repatriate children depend a lot more on their mothers compared to their fathers, or to their parents who are looking after them (since the present study showed that $44.6 \%$ of repatriate spouses were male). Repatriate children also tend to preoccupy themselves with many things and seldom take notice of their parents' working life, and they also seldom take notice of their parents' readjustment process.

In all, it can be said that repatriate children do not know much of what their parents are doing or going through during the readjustment process. They themselves are too busy readjusting their lives to their new schools, hobbies, environment, weather, friends and teachers which naturally consume a lot of their time. Therefore, no significant relationship was found in the relationship between repatriate children's readjustment and repatriates' readjustment.

\subsection{Repatriate Children's General Readjustment and Repatriates' Psychological Well-being}

As predicted, the findings in the present study indicated a significant relationship between repatriate children's general readjustment and repatriates' psychological well-being. This is in line with Ali (2003), in which he found that there was a significant relationship between expatriate's and children's intercultural adaptation. Thus, the researcher can say that repatriate children who have a good level of general readjustment may influence repatriates' psychological well-being. Repatriate children who were not able to readjust to new schools, friends, teachers and surroundings will be disturbed psychologically and sensing this situation, repatriates would also be affected psychologically. The results also indicated that the repatriates had taken care of their children's general readjustment during the repatriation process. 


\section{Conclusion}

The title of this paper is, 'Repatriate children's readjustment to the home country and the impact on repatriates' readjustment". The researcher has proven that the research question has been answered: that the repatriate children are important for repatriates to readjust to the home country. The factors such as general readjustment and the well-being of the children's general health and general readjustment are some of the factors that make the repatriation process successful. Even though job factors are important to repatriates, family members must be considered as one of the successful factors on the repatriation process. The present study's findings highlight that it is a must for repatriates to consider the success of the readjustment process of their family members when they return to their home country. This is important since the readjustment process of their family members will lead to the success in their career. In general, the researcher can conclude that, in every successful repatriate there are his/her children who have been successfully readjusted to the home country.

\subsection{Implications}

In this section, the implications of the present study are divided into four groups which are repatriates, repatriate children, organizations and literature.

\subsubsection{Implications for Repatriates}

Repatriates with families need to know that their children's readjustment process to their home country is a very important issue since if they are not able to readjust they will give a significant impact later to repatriates' work and life. Thus, this goes to prove that children definitely need attention from their partners and parents so it may be not an easy process for them to readjust to the home country.

\subsubsection{Implications for Repatriate Children}

The present study found that in order to have a high level of general readjustment, repatriate children must possess high level of satisfaction with new friends and acquaintances that they make in the home country. Repatriate children can make new friends at their school and also in their neighbourhood. Repatriates should encourage their children to mix around and develop friendships quickly since being satisfied with new friends and acquaintances has been found to be the strongest predictor of repatriate children's general readjustment. It will not be easy for repatriate children to say goodbye to their previous friends in the host country, but in order to start a new life in the home country, repatriate children need to develop new friendships and be happy and satisfied with the relationships.

Repatriate children have many stories of expatriation experiences to tell their friends at school and these experiences will make them well-known and received at schools and also in the neighbourhood. In addition, these new friends are important since they also provide support to repatriate children to readjust to the new school, hobbies, food, teachers at school and the environment in general. There must be a few local children who would not like them, but they should take this as a challenge in order to find better friends. In addition, repatriate children must also be aware that not all children in the home country would accept them as they are. Repatriate children must have learnt new skills and hobbies while expatriating and their experiences are a little bit different from the local children in the home country. Some repatriate children also must have learnt new languages while expatriating if they followed local schools in the host country. The other repatriate children attended international schools in the host country in which English language is the medium of conduct. By this, repatriate children are able to communicate fluently in other languages or the English language and they may face difficulties in understanding the local language of the home country after a few years of living overseas. This situation somehow brings negative impact to repatriate children. Some children at schools or the neighbourhood will shy away from them while others may hate them. Repatriate children, thus, need to find a circle of friends who can accept them the way they are. School life in the home country can be a bit challenging for the repatriate children.

One Malaysian repatriate spouse that the researcher had interviewed mentioned that her two sons were having a few difficulties at school. They have lived in New York for seven years and the two sons had adhered to the American schooling. Their handwriting had become a big issue among teachers at school when they returned to Malaysia. Their handwriting was in big font, compared to the local students because that was the way they were taught at their school in New York. Another humorous story and yet challenging one, is that because their physical features are different (that is, a bit fair, good looking and charming), they were popular among girls at school. Girls sent them love letters and one day a teacher saw one of the letters and sent one of the sons to the headmaster. Of course, the son defended himself by saying it was not his fault. It was the girls' fault who sent him the love letters. Another challenging story that the two sons had was that a few times in the classes, they tried to correct their English teachers and the teachers became angry with them and asked them to stand outside 
of the classroom for one hour. This incident had occurred repeatedly and the two young boys had become discouraged by their English teacher's attitude.

Interestingly, for repatriate children's general health, again satisfaction with new friends and acquaintances in the home country appeared to be the strongest antecedent. In addition, the dismissive-avoidance attachment style also emerged as a predictor of repatriate children's general health. Individuals with dismissive-avoidant attachment style demonstrate a sense of love-worthiness, but this is mixed together with a negative disposition against other people (Bartholomew, 1990). These people defend themselves against disappointment by keeping away from close relationships and maintaining self-independence. In this case, repatriates and their spouses need to pay attention to their children's characteristics. If they feel that their children fall in this category, then, repatriate parents should encourage their children to develop friendship with as many friends as possible and later pick a circle of friends that suits them the most.

If repatriate children are not able to make and develop their circle of friends, they may feel disappointed and sad. The tendency to get sick will be higher if they do not like friends at school or in the neighbourhood. This situation may lead repatriate children to suffer from low self-esteem, lack of self-confidence, become angry easily and want to be left alone (Storti, 2003). Thus, it is important for repatriate children to find their circle of friends since if they are not able in doing so, it will lead to negative impact on their general health.

In order to increase the general health of repatriate children, repatriate parents must pay attention to the dismissive-avoidant attachment styles among their children. Repatriate children will feel disappointed if they are not happy and they will be sick a lot more if they do not like and are not satisfied with friends in the home country. This situation will lead to repatriate children's developing low self-esteem, lack of self-confidence, becoming angry easily, wanting to be alone and later on for them, everything will look bad in the home country.

\subsubsection{Implications for Organizations}

Even though the present study did not examine the effect of support from international companies on repatriates and their family members' readjustment, the researcher hopes that companies will keep on supporting the repatriates and their family members, especially during the first few months of the repatriation period. The present study has shown that a few antecedents are important for the general readjustment and general health of the children. International companies could use the results of the present study to draw new policies regarding the repatriation process, especially the ones that involve both repatriate children. It is not only the repatriates who need some training before and after returning to their respective home country. Repatriate children need them too and are encouraged to follow some training as a form of aid to assist them in their readjustment process of returning to the home country.

The researcher would also like to suggest the international companies to sponsor a visit to the repatriates and their family members to go back to their home country, and this can be an annual sponsorship. The visits will help the repatriates and family members to reconnect and get in touch with their families and friends back home, as recommended by Selmer (1995) and Siljanen (2009).

In addition, the researcher would also like to recommend international companies to establish a network among the companies' repatriates so a 'support' group is there whenever new repatriates return to the home country. In this network, someone senior with repatriation experiences can be a mentor to the newly returned repatriates. This repatriate's mentor-mentee program will help the repatriates and their family members when they are facing some difficulties and at least, they have a place to turn to when they need some advice.

Peng (2009) suggested that the International Human Resource Department of international companies should focus on $4 \mathrm{C}$ 's in order to make their department become more effective and efficient. The 4Cs' are curious, competent, courageous and caring:

- Be curious- they need to know formal and informal rules of the game governing the HRM in all regions of operations.

- Be competent- they need to develop organizational capabilities that drive business success.

- Be courageous and caring- as guardian of talent, HR managers need to nurture and develop people

Thus, by referring to the 4 C's above, Human Resource department needs to be proactive in channelling their support to the repatriate families.

\subsubsection{Implication for Literature}

The present study has shed some light on the antecedents that contribute to repatriate children's readjustment process to their home country. This topic has received little attention from the scientific research and the present 
study has contributed ample empirical evidence to the literature with regard to the repatriate family members' readjustment field. On top of that, the present study has indicated that the repatriate children's readjustment contributes to repatriates' own readjustment to the home country.

\subsubsection{Recommendations for the Future Studies}

It would be beneficial to conduct a longitudinal study in which more conclusive results will be attained. The present study managed to highlight and reveal a number of antecedents to repatriate children's readjustment to the home country. However, the researcher would recommend future studies to group the respondents according to their hosts and home countries. The researcher believes that more interesting results will be established by grouping the respondents to their homes and host countries. In terms of the cultural background of the respondents, probably future research should consider analysing the data according to the cultural background of the respondents. By doing this, a more accurate picture of repatriate family members' situations of the readjustment process would be obtained. In addition, future research should also separate the respondents according to the last country that they have resided before they returned to their home countries. This is because the readjustment process to the home country would be different for repatriates who have expatriated in a host country better than their home country or in a host country that is more underdeveloped than their home country. Future studies are also recommended to translate the questionnaires into a few major languages of the world. The questionnaires are encouraged to be translated at least to three major languages such as Mandarin, Spanish and French. The present study has to some extent, succeeded in distributing the questionnaires all over the world. However, it is proposed that the future research needs to find ways to distribute the questionnaires all over the world extensively. The researcher believes that with enough fund and contacts, this recommendation would be realized.

\section{References}

Ali, A. J. (2003). The intercultural adaptation of expatriate spouses and children: An empirical study on the determinants contributing to the success of expatriation. The Netherlands, Labyrint Publication.

Bartholomew, K. (1990). Avoidant of intimacy: An attachment perspective. Journal of Social and Personal Relationships, 7, 147-178. http://dx.doi.org/10.1177/0265407590072001

Bartholomew, K., \& Horowitz, L. M (1991). Attachment styles among young adults: A test of a four-category model. Journal of Personality and Social Psychology, 61(2), 226-244. http://dx.doi.org/10.1037/0022 $-3514.61 .2 .226$

Black, J. S. (1988). Work role transitions: A study of American expatriate managers in Japan. Journal of International Business Studies, 19, 277-294. http://dx.doi.org/10.1057/palgrave.jibs.8490383

Black, J. S., \& Gregersen, H., Mendenhall, B., \& Mark, E. (1992). Toward a theoretical framework of repatriation adjustment. Journal of International Business Studies (p. 737). http://dx.doi.org/10.1057/ palgrave.jibs. 8490286

Black, J. S., \& Stephen, G. K. (1989). The Influence of the spouse on American Expatriate adjustment in overseas assignments. Journal of Management, 15, 529-544. http://dx.doi.org/10.1177/014920638 901500403

Dowling, P. J., Welch, D. E., \& Schular, R. S. (1999). International Human Resource Management: Managing People in a Multinational Context (3rd ed.). Cincinnati, OH: South-Western College Publishing.

Engen, J. R. (1995). Coming Home. Training, 32(3), 37-40.

Fish, A., \& Wood, J. (1997). Managing spouse partner preparation and adjustment; developing a meaningful life. Personnel Review, 26(6), 445-466. http://dx.doi.org/10.1108/00483489710188874

Gregersen, H. B., \& Stroh, J. K. (1997). Coming home to the arctic cold: Antecedents to Finnish expatriate and spouse repatriation adjustment. Personnel Psychology, 50, 635-654. http://dx.doi.org/10.1111/j.1744 $-6570.1997 . t b 00708 . x$

Hair, J. E., Anderson, R. E., Tatham, R. L., \& Black, W. C. (2006). Multivariate Data Analysis (5th ed.). Upper Sadler River: Prentice Hall.

Harvey, M. G. (1989). Repatriation of corporate executives: An empirical study. Journal of International Business Studies, 19, 131-144. http://dx.doi.org/10.1057/palgrave.jibs.8490355

Hunt, D. M., \& Bolon. (1998). A framework for studying and improving the human resource repatriation practices of expatriates from all nation. Retrieved from http:॥www.sbaer.uca.edu/Research/1998/ 


\section{SRIBR/98sri059.txt}

Mikulincer, M., \& Florian, V. (1998). The relationship between adult attachment styles and emotional and cognitive reactions to stressful events. In J. A. Simpson, \& W. S. Rholes (Eds.), Attachment Theory and Close Relationships (pp. 143-165).

Oberg, K. (1960). Culture shock: Adjustments to new cultural environments. Practical Anthropology, 177-182.

Paik, Y., Segaud, B., \& Malinowski, C. (2002). How to improve repatriation management. Are motivation and expectation congruent between the company expatriates? International Journal of Manpower, 23(7), 635-648. http://dx.doi.org/10.1108/01437720210450815

Parker, B., \& McEvoy, G. M. (1993). Initial examination of a model of intercultural adjustment. International Journal of Intercultural Relations, 17(3), 335-379. http://dx.doi.org/10.1016/0147-1767(93)90039-B

Peng, M. W. (2009). Global Business. Canada: South-western, Cengage Learning.

Rokeach. (1973). The nature of human values. New York: Free Press.

Schwartz, S. H. (1992). Universals in the context and structure of values: Theoretical advances and empirical test in 20 countries. In M. Zanna (Ed.), Advances in experimental social psychology (Vol. 25, pp. 1-65).

Searle, W., \& Ward, C. (1990). The prediction of psychological and sociocultural adjustment during cross-cultural transitions. International Journal of Intercultural Relations, 14(4), 449-464. http://dx.doi.org/10.1016/0147-1767(90)90030-Z

Segall, M. H., Dasen, P. R., Berry, J. W., \& Poortinga, Y. H. (1999). Human Behavior in Global Perspective: An Introduction to Cross Cultural Psychology. Boston: Allyn and Bacon Press.

Selmer, J. (1995). Expatriate Management: New Ideas for International Business. Quorum Books, Connecticut.

Siljanen, E. M. (2009). Exploring the repatriation of Finnish Civilian Crisis Management personnel and Introducing a Conceptual Framework of repatriation Process. Unpublished thesis, University of Kuopio, Japan.

Solomon, C. (1995). Repatriation: up, down or out? Personnel Journal, 28-30, 32-35, 37.

Storti, C. (2003). The Art of coming Home (pp. 103-135). Boston: Intercultural Press.

Stroh, L., Gregersen, H., \& Black, S. (1998). Closing The gap: Expectation versus reality among repatriates. Journal of world Business, 111-124. http://dx.doi.org/10.1016/S1090-9516(98)90001-3

Usunier, J. C. (1998). Oral pleasure and expatriate satisfaction: An empirical approach. International Business Review, 7(1), 89-110. http://dx.doi.org/10.1016/S0969-5931(97)00053-X

Van der Zee, K. I., Ali, A. J., \& Haaksma, I. (2007). Determinants of intercultural adjustment among expatriate children. Anxiety, Stress and Coping: An International Journal, 20(1), 25-45. http://dx.doi.org/10.1080/ 10615800601032781

Zhang, N., \& Rentz, A. L. (1996). Intercultural adaptation among graduate students from the People's Republic of China. College Student Journal, 30(3), 321-329.

\section{Copyrights}

Copyright for this article is retained by the author(s), with first publication rights granted to the journal.

This is an open-access article distributed under the terms and conditions of the Creative Commons Attribution license (http://creativecommons.org/licenses/by/3.0/). 